\title{
Comprehensive Analysis on Flipped Classroom to English Teaching in China's Universities
}

\author{
Zhang Ting \\ Urban Vocational College of Sichuan
}

Keywords: Flipped Classroom; China's Universities; English Teaching; Research Comprehensive Analysis

\begin{abstract}
Currently, universities are increasingly paying attention to English Teaching, trying to use a new teaching method to improve the classroom efficiency. The new mode of flipped classroom has been used during the teaching process in many key universities. Therefore, the real essence as well as the value of flipped classroom should be deeply understood when it is applied during teaching. The western developed countries were the first to apply flipped classroom in the teaching process. With many years of practice and experience, China has now applied this kind of mode in many teaching fields and has taken the delectable achievement. Therefore, the achievements should be deeply analyzed and discussed to promote the optimization of English teaching in universities.
\end{abstract}

\section{Preface}

The word flipped classroom first occurred in America. This kind of teaching mode was by then a way to deal with all kinds of interference factors which exert the students' attention. At that time, the teaching process in classroom was recorded for those students who cannot study on site. In this way, the students can conduct autonomous learning without space or time limitation. After many years of practice and application, many countries begun to apply the mode of flipped classroom. This was highly applauded by peers and students.

\section{Implication of Flipped Classroom}

Flipped Classroom is now the most popular teaching method which has win favors of students and teachers home and abroad. By presenting the teaching resources in ways of internet, flipped classroom has solved the students' great barrier of not being able to learn in classroom. The contemporary students pursues free learning mode because they are learning to enrich themselves. Therefore, they will tend to choose courses with high degree of freedom. The explanations of knowledge points in these courses are detailed so that the students will feel relaxed during the learning process. The students do not have a deep understanding of English since it is a foreign language. What's more, some uncoordinated problems among the teachers and the students have made the learning process much more difficult, leading to the students' tired of learning situation. To adapt to such kind of situation, flipped classroom can be a new teaching method the students use to study English. It is out of the traditional teaching. Through flipped classroom, the students can study during times after class through videos or e-books, etc. The knowledge points are detailed. Less time of the students would be occupied, making it much more unconstrained. What's more, the traditional teacher-to-student mode has been converted to teaching-to-student or student-to-student, which can improve the students' interactive ability. The students can raise questions through bullet screen. What's more, the interactive learning among the students can improve their understanding towards the knowledge, making the learning process much more interesting. Micro-course is the main body of flipped classroom. The knowledge points are divided into many pieces and unscrambled one by one so that the knowledge which should be grasped by the students could be imparted step by step. In this way, the students can have stronger understanding of the knowledge point. What's more, the students won't be troubled by the problem that they cannot learn the next 
point well if they have missed some points. Their learning efficiency and enthusiasm towards learning are greatly improved. This kind of teaching mode is originated from America and is now introduced to China to improve the Chinese students' learning ability because of its great effects.

\section{Meaning and Advantage of Flipped Classroom in English Teaching in Universities}

Flipped classroom refers to the learning way that the students study the knowledge within their spare time through videos or lectures. This kind of teaching mode has effectively improved the students learning efficiency and strengthened their innovative practical ability. Since the economy in China is developing rapidly, how to cultivate innovative talents has become the immediate problem. Traditional teaching mode is inclined to the teaching of theoretical knowledge and has neglected the cultivation of the students' innovative practical ability. Therefore, the traditional teaching mode will certainly be replaced. Flipped classroom is a teaching mode combining modern technology, and many universities have now apply it in English teaching and have achieved great results. English is the weak subject of many college students. It mainly takes three steps to learn English: oral English, words and grammars. It is relatively easy for the students to memorize the words, and the main question lies in spoken English and grammar. In spoken English, correct pronunciation is required. While in grammar, understanding. However, the difference between Chinese and foreign culture, as well as the variety of teachers' ability makes it really hard for the students to learn. Flipped classroom, however, will make spoken English or grammar into small videos or lectures held in school so that the students can enrich the knowledge during spare time without influencing their study in class. What's more, flipped courses can be used repeatedly, so we don't need to worry that the students might not understand it. The combination of flipped classroom in English teaching will effectively improve the students' learning efficiency. Therefore, the universities should extensively make use of flipped classroom to conduct English teaching to improve the students' English.

The purpose of flipped classroom is to improve the students' learning ability. Therefore, the knowledge point will be divided into several pieces so that the students can understand the knowledge much more easily. There are reasons for the students' poor English ability. First, it is difficult to learn a second language. Second, to complete the teaching tasks, teachers won't pay more attention to those students who are weak in English, leading to snowball effect. Their academic record will be worse and worse. Flipped classroom, however, is to record the material in class with modern technology. The explanation of English knowledge is very detailed, taken part of speech as an example. In flipped classroom, verb, noun and adjective, and so on, are explained in individual video. In this way, it is much more detailed and it is easy for the students to look for the point and study again. The students will definitely understand the knowledge as long as they actively try to learn, and they will improve their study by studying the questions which were not understood during class. A positive cycle will then be formed to effectively improve the students' comprehensive English ability.

The greatest trait of flipped classroom is that no specific space is needed since most of the contents taught by the teachers were recorded and permanently saved in the Internet platform for the students. The convenience of study is improved. Some students, due to their own characteristics, won't ask the teacher for help after class if they encounter some questions. At such time, flipped classroom can play the role of teachers and solve the students' problems. Science indicates that people's intelligence quotient does not vary that much. Therefore, the performances of students are decided by their ability to acquire knowledge in class. Flipped classroom is created for this. If the students failed to understand some of the points in class, they can make use of some spare time to study online so that they can keep up with the teachers' teaching process and improve their study quality.

Being the subject in flipped classroom, the students improved their interests in study. The reason why traditional teaching mode has non-ideal quality of teaching is that teachers role in learning is overemphasized, and that the teachers subjectivity allocate the learning resources, making the students learning in a passive way with relatively low interest. It is obvious that this kind of 
teaching mode is not applicable in the modern society which is open. No one will influence the students' learning consciousness in flipped classroom since they conduct learning all by themselves and their leading role in study is fully demonstrated. The essence of flipped classroom is simplicity. It does not require the students to grasp a great deal of knowledge in a short period of time, but to grasp a small knowledge point as soon as possible. What's more, the software will set homework for the students according to what they have learnt. They won't have too much homework since this is only set to strengthen the students. All in all, this software is mainly a helping tool during the students' learning, aiming to improve the students' interest towards study.

\section{Comprehensive Analysis of Flipped Classroom to English Teaching in China's Universities}

The production of flipped classroom has great influence on the students' learning efficiency. Therefore, the topic should be strictly chosen. Students' main purpose of learning is to enrich themselves. However, an ideal grade makes it possible for them to get to a bigger platform. Thus, the topics should be of pertinence and help the students to know the hot tests so that they can take the exam unhurriedly. The students will be able to draw inferences about other cases from one instance according to what they have learnt in macro class. In this way, their ability of solving problems will be improved. Hot tests points are also included in the traditional teaching way. However, those are neatened by the teachers and are of no pertinence. The most detailed explanation, however, can be done. One class could be set for each testing point so that the students can review specifically. It takes not only effort, but also correct way to improve study performance.

Compared to traditional teaching, the greatest merit of flipped classroom lies in the explanation of the knowledge points. We use micro before micro class because it has many courses, and the knowledge points are divided into many pieces to be detailedly explained. The students are able to see the structure of a great knowledge point concisely and to remember the points as well as some problem-solving skills. At the same time, some questions will be set so that the students can solve the problems at the time they watch the classes to reinforce what they have learnt. With the vigorous development of the new era, our society has entered a fast-paced one. The topics chosen should be as detailed as possible and should be controlled within 10 minutes. While learning these language points, the students' normal study should not be influenced. It should be used as an analyzing method to improve the students' knowledge reservation.

To better apply the interactive teaching mode in senior English classes, the teachers perspectives should be analyzed. The teachers should well define their position, optimize their teaching idea and adjust their previously used teaching mode to provide a high quality interactive teaching class for the students. The teachers should help the students to deal with their subjective position and actively carry out interactive classes in a subsidiary role. They should take classroom interactive activities as the main part in teaching to improve the students' property of participation and enthusiasm during the studying process. What's more, they should extend the students' scope knowledge during interactive teaching, helping the students to find more knowledge in the English material.

During the English teaching process in universities, the students should not only make themselves master of knowledge points in the teaching materials, but they should also improve their proficiency level. As a language, English cannot be simply classified as a subject. In interactive teaching mode, more communication platforms are provided to the students. For example, group discussion, desk-mate mutual learning, or free speech process are all key to cultivate the students' language applied ability. They key to comprehensively improve the students language applied ability is that the teachers should realize effective interactive teaching during the students' question analyzing or thinking process during interactive part in class.

\section{Conclusion}

China's society has changed dramatically, so students' learning styles need to adapt to changing times. Flipped classroom can improve the students learning ability and strengthen students' ability to interact. Micro class is the main body of flipped class, and it is also the way students use to learn 
knowledge. The students can watch the micro classes by videos or e-books and grasp some knowledge points in a short period of time. The conduction of micro classes in universities should be in accordance with the students' learning situation and should not be done with some difficult contents that the students can hardly understand. The topics chosen should be of pertinence, with as many as hot test points chosen. These knowledge points should be divided into pieces to help the students to grasp it.

\section{References}

[1] Xue Shuling, Comprehensive Analysis on Flipped Classroom to English Teaching in China's Universities [J], New Course (Primary School), 2014, (3);

[2] Dai Pingping, Comprehensive Analysis on Flipped Classroom to English Teaching in China's Universities [J], Society, 2015, (6);

[3] Ma Zhaojie, Comprehensive Analysis on Flipped Classroom to English Teaching in China's Universities [J], New Curriculum Reform, 2013, (3);

[4] Li Ping, Discussion on Flipped Classroom to English Teaching in China's Universities [J], Chinese Class, 2015, (6);

[5] Shen Juan, Comprehensive Analysis on Flipped Classroom to English Teaching in China's Universities [J], Western Quality Education, 2016, (10);

[6] Wang Xiaona, Comprehensive Analysis on Flipped Classroom to English Teaching in China's Universities [J], Learning Weekly, 2016, (20);

[7] Wang Ziying, Countermeasures of Comprehensive Analysis on Flipped Classroom to English Teaching in China's Universities [J], Northeast Normal University, 2010.

Brief Introduction of the Author: Zhang Ting was born on June 28th in 1980 and she is from Chengdu City, Sichuan Province. She is a master and is now working in Urban Vocational College of Sichuan. Here research interest is English teaching.

Address: Room 1-3-202 of Runyang Jinsha 30 Degree, No. 5 on Huangzhong Bystreet, Chengdu City, Sichuan Province

Tel.: 18981873628 